\title{
PERANCANGAN SISTEM KOMUNIKASI DATA ALAT PENCATATAN METER AIR DIGITAL BERBASIS SERVICE ORIENTED ARCHITECTURE
}

\author{
Yaddarabullah, Dewi Lestari \\ Program Studi Teknik Informatika, Fakultas Industri Kreatif dan Telematika, Universitas Trilogi \\ Jl.TMP Kalibata No.1, Jakarta, Indonesia \\ yaddarabullah@trilogi.ac.id, dewy24@trilogi.ac.id
}

\begin{abstract}
Abstrak - Sistem pemantauan meter air PDAM saat ini masih dilakukan secara manual, yaitu pemantauan meter air dilakukan dengan dikunjungi oleh petugas PDAM secara berkala dalam sebulan sekali sehingga pencatatan meter air rentan dari kesalahan dan tidak akurat. Teknologi internet of things dapat menjadi solusi dalam pencatatan meter air, dengan demikian pencatatan dapat dilakukan secara otomatis dan dapat dipantau langsung dari aplikasi. Pencatatan data dari perangkat internet of things kedalam aplikasi membutuhkan sistem komunikasi data antara lain MQTT dan Socket Connection. Namun sistem komunikasi data yang telah dipakai memiliki kekurangan yaitu tidak dapat dikustomisasi untuk multiplatform. Pada penelitian ini dilakukan riset dan pemodelan terhadap penggunaan sistem komunikasi data yang lain yaitu Service Oriented Architecture agar dapat mendukung multiplatform yang diaplikasikan pada perangkat pencatatan meter air PDAM.
\end{abstract}

Keywords - Service Oriented Architecture; Internet of Things; Sistem Komunikasi Data.

\section{PENDAHULUAN}

Perkembangan teknologi internet of things yang diterapkan pada smart city semakin berkembang. Hal tersebut berdasarkan data prediksi yang di keluarkan oleh International Data Corporation (IDC) mengekspetasi pertumbuhan penggunaan perangkat internet of things dari tahun 2013 sampai tahun 2020 sebesar $17.5 \%$ pemasangan perangkat internet of things sampai 28.1 juta [1]. Salah satu perangkat yang di terapkan dalam smart city adalah pencatatan meter air secara digital dan dapat di pantau melalui aplikasi yang terhubung ke internet. Alat pencatatan meter air tersebut dilengkapi dengan sensor flow meter dan mkirokontroller. Beberapa penelitian telah dilakukan untuk merancang alat tersebut termasuk komunikasi data agar dapat di akses melalui aplikasi antara lain sebagai berikut.

Pertama, komunikasi data mengunakan pengiriman SMS dari alat pencatatan meter air digital ke gateway yang ada di server [2]. Dalam penelitian ini memiliki kelemahan yaitu membutuhkan pulsa yang harus disediakan pada alat pencatat meter air sehingga membutuhkan biaya yang banyak untuk mengisi pulsa. Dampaknya durasi pengiriman data harus dibatasi dalam periode tertentu. Selain itu untuk dapat diakses melalui aplikasi dibutuhkan tambahan service yang mengakses server SMS. Hal ini menyebabkan pembacaan data menjadi tidak realtime.

Kedua, komunikasi data menggunakan modul wifi yang terkoneksi langsung ke smartphone [3] juga memiliki kelemahan yaitu mengakibatkan pemantauan hanya dapat dilakukan oleh pelanggan meter air, sehingga pemantauan oleh petugas dan operator masih menggunakan cara manual yaitu dengan cara mencatat meter air langsung ke lokasi pelanggan. Hal ini dapat menyebabkan ketidaksesuaian antara meter air yang tercatat di aplikasi dengan yang dicatat oleh petugas.

Ketiga, komunikasi data menggunakan protokol Message Queue Telemetry Transport (MQTT) untuk pengiriman data ke gateway [4]. Pada penelitian ini membutuhkan gateway yang berfungsi sebagai penyimpan data sementara yang dikirim oleh alat pencatatan meter air. Dalam periode tertentu data dari gateway akan dikirim ke server hosting untuk dapat diakses melalui aplikasi. Metode ini memiliki kelemahan yaitu jika jarak antara alat pencatatan meter air yang jauh dari gateway maka mempengaruhi kecepatan transfer data dan data hanya dapat di akses melalui satu platform gateway saja sehingga untuk dapat diakses melalui platform gateway yang berbeda harus membuat service tambahan. Kelemahan lainnya yaitu untuk dapat diakses dari aplikasi diperlukan tambahan service yang mengakses ke gateway.

Berdasarkan masalah dalam penelitian terdahulu tersebut maka diperlukan perancangan sebuah metode dalam sistem komunikasi data pada alat pencatatan meter air digital yang dapat digunakan untuk pengiriman data secara realtime dengan durasi pengiriman data yang cepat dan kecepatan transmisi data yang tinggi, kemudian pemantauan penggunaan air dapat dilakukan oleh pelanggan dan petugas melalui aplikasi multiplatform. Dalam penelitian ini akan diteliti penggunaan Service Oriented Architecture (SOA) pada sistem komunikasi data alat pencatatan meter air digital.

\section{Metode Penelitian}

Pada penelitian ini dibutuhkan perlengkapan untuk merancang alat pencatatan meter air digital sebagai berikut: Arduino UNO R3, sensor flow meter, GSM Modem SIM900A, 
LCD 16x2 dan penggunaan server hosting untuk penyimpanan dan pengaksesan data. Berikut adalah diagram rangkaian alat pencatatan meter air digital.

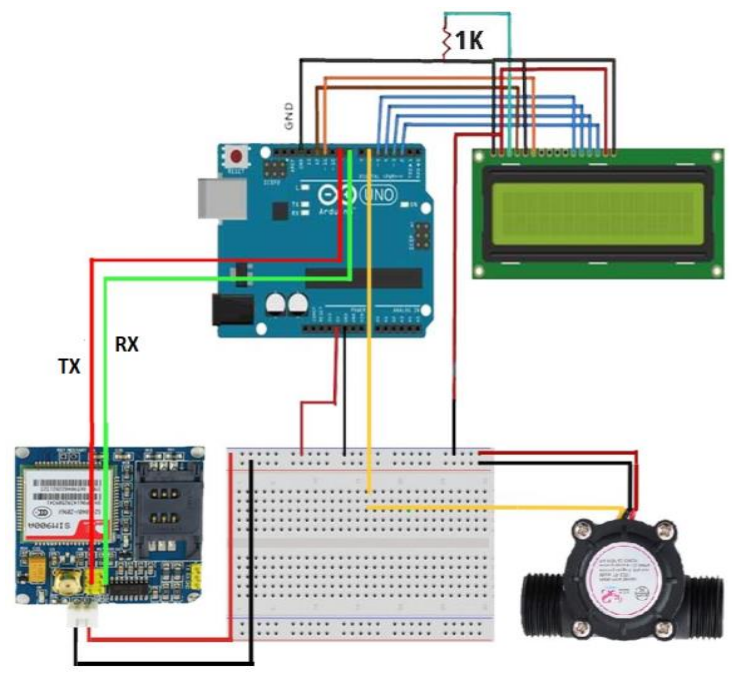

Gbr. 1 Diagram Rangkaian Alat Pencatatan Meter Air Digital

TABEL I

KETERANGAN PEMASANGAN LCD 16X2 KE ARDUINO

\begin{tabular}{|l|l|}
\hline \multicolumn{1}{|c|}{ Arduino UNO R3 } & \multicolumn{1}{c|}{ LCD 16x2 } \\
\hline Pin 1 & Ground \\
\hline Pin 2 & $+5 \mathrm{v}$ \\
\hline Pin 3 & 1K ohm resistor - GND \\
\hline Pin 4 & Register Selected \\
\hline Pin 5 & Read/Write \\
\hline Pin 6 & H/L Enable \\
\hline Pin 11 & DB4 \\
\hline Pin 12 & DB5 \\
\hline Pin 13 & DB6 \\
\hline Pin 14 & DB7 \\
\hline
\end{tabular}

TABEL III

KETERANGAN PEMASANGAN SENSOR Flow METER KE ARDUINO

\begin{tabular}{|l|l|}
\hline \multicolumn{1}{|c|}{ Arduino UNO R3 } & \multicolumn{1}{c|}{ Sensor Flow Meter } \\
\hline GND & Kabel Hitam (GND) \\
\hline VCC 5v & Kabel Merah (VCC) \\
\hline Pin 7 & Kabel Kuning \\
\hline
\end{tabular}

TABEL IIIII

KETERANGAN PEMASANGAN MODUL GSM SIM900A KE ARDUINO

\begin{tabular}{|l|l|}
\hline \multicolumn{1}{|c|}{ Arduino UNO R3 } & \multicolumn{1}{c|}{ Modul GSM SIM900A } \\
\hline GND & Kabel Hitam (GND) \\
\hline VCC 5v & Kabel Merah (VCC) \\
\hline Pin 9 & RX \\
\hline Pin 10 & TX \\
\hline
\end{tabular}

Berikut adalah diagram proses pembacaan volume dan debit air pada alat pencatatan meter air digital.

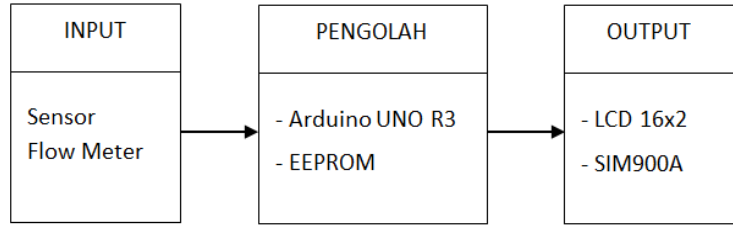

Gbr. 2 Diagram Proses Pembacaan Volume dan Debit Air

Sensor flow meter berfungsi untuk mendeteksi aliran air yang melewati sensor. Pada penelitian ini menggunakan sensor flow meter dengan ukuran diameter $1 / 2$ meter. Rangkaian sensor flow meter ditunjukan pada gambar 3 .

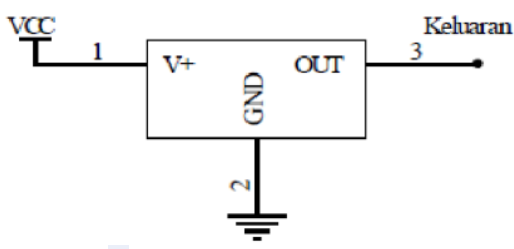

Gbr. 3 Rangkaian Sensor Flow Meter

Sensor flow meter ini membutuhkan tegangan sebesar $5 \mathrm{v}$ DC dan arus sebesar 15-20 mA. Tekanan air yang dapat dibaca maksimal 2.0 $\mathrm{MPa}$, kelembaban 35\%-90\% RH dan suhu air $120^{\circ}$. Kemampuan sensor ini dapat membaca 100 sampai $150 \mathrm{~L} / \mathrm{min}$ [5]. Data output dari sensor berupa pulsa yang nantinya akan di proses oleh Arduino UNO R3 untuk melakukan penghitungan debit dan volume air. Berikut persamaan yang digunakan untuk mendapatkan volume air dalam satuan liter [6].

$$
F R=\frac{(1000.0 \times p C)}{c F}
$$

Keterangan:

$\mathrm{FR}$ = rata-rata aliran (flowrate)

$\mathrm{pC}=$ nilai byte hasil dari pembacaan oleh sensor $\mathrm{cF}=4.5$ adalah nilai kalibrasi.

Persamaan kedua digunakan untuk mengkonversi dari FR menjadi volume.

$$
V=(F R / 60) \times 1000
$$

Keterangan:

$\mathrm{FR}=$ rata-rata aliran yang terbaca oleh sensor

$\mathrm{V}=$ Volume air yang terbaca dalam satuan liter

Persamaan ketiga digunakan untuk mendapatkan debit air dalam satuan liter.

$$
D=V * 10
$$

Keterangan:

$\mathrm{D}=$ Debit air dalam satuan liter

$\mathrm{V}=$ Volume air dalam satuan liter

Selanjutnya data tersebut disimpan kedalam memori EEPROM yang ada di Arduino UNO R3. Kapasitas 
penyimpanan data EEPROM pada Arduino UNO R3 sebesar 1024 bytes [7]. Kemampuan membaca dan menulis ke dalam EEPROM adalah sebanyak 100.000 kali. Selain itu, EEPROM juga dapat digunakan untuk menyimpan data-data informasi inisialisasi Arduino, seperti serialnumber dan tanggal manufaktur. Data volume setelah disimpan ke dalam EEPROM selanjutnya ditampilkan ke LCD 16x2.

Tahapan selanjutnya adalah merancang database dan table di server. Dalam database terdiri dari table-tabel yang akan digunakan untuk mengolah data meter air dari alat pencatatan dan berfungsi untuk menyediakan data yang akan di akses melalui web dan aplikasi mobile. Berikut adalah diagram relasi table ditunjukkan pada gambar 4 .

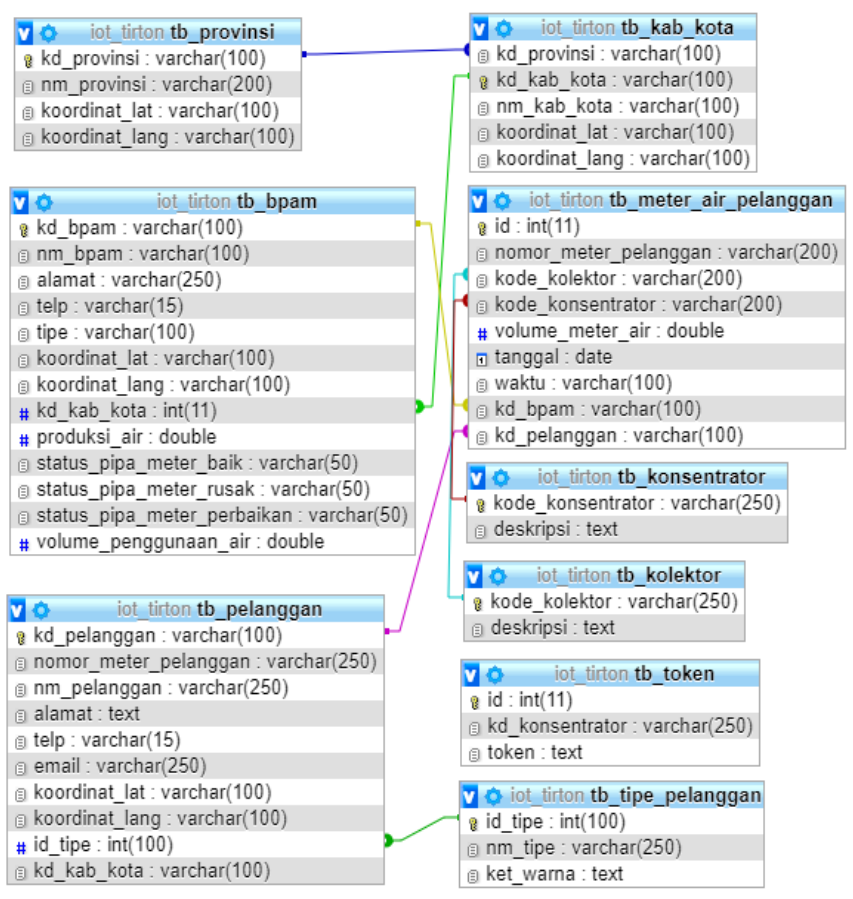

Gbr. 4 Diagram Relasi Tabel

Tahapan selanjutnya adalah menyiapkan arsitektur komunikasi data untuk pengiriman data dari alat pencatatan meter air digital ke server menggunakan Service Oriented Architecture.

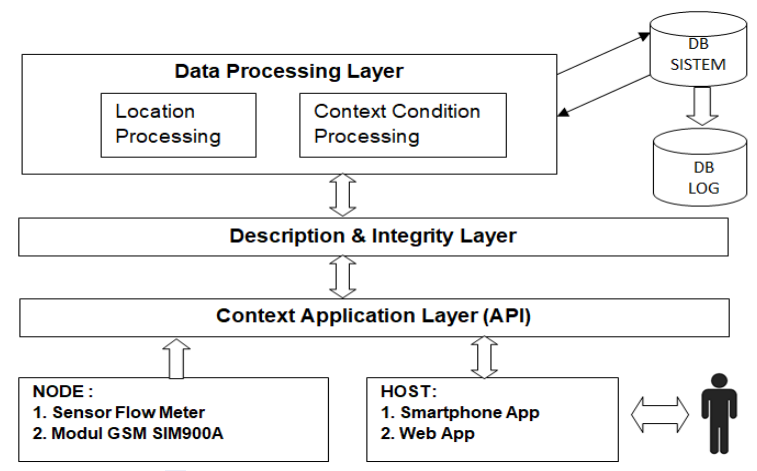

Gbr. 5 Rancangan Service Oriented Architecture

A. Node
Node adalah alat pencatatan meter air digital. Pada setiap node terdiri dari mikrokontroller Arduino UNO R3, sensor flow meter, modul GSM SIM900A, LCD 16x2. Penggunaan mikrokontroller tidak hanya dapat menggunakan Arduino UNO R3, tetapi bisa menggunakan mikrokontroller lainnya seperti Raspberry Pi atau ATMega. Secara periodik node akan mengirimkan data melalui modul GSM SIM900A ke Context Appliation Layer. Data yang dikirim ke alamat URL melalui protokol HTTP. Berikut format dan alamat URL yang digunakan untuk pengiriman data dari node.

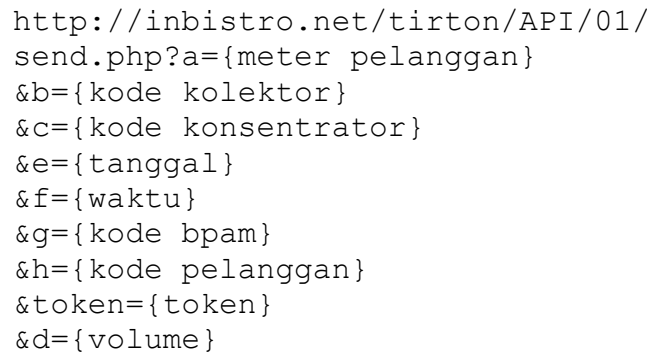

\section{B. Context Application Layer (API)}

Context Application Layer memiliki tiga fungsi yaitu pertama sebagai layer yang menerima dan memproses data yang dikirim oleh node atau host. Pembacaan request dengan melalui mengakses URL dari alamat service. Output dari respon adalah data dalam format JSON. Berikut data dalam format JSON yang dihasilkan dari data yang telah dikirim oleh node.

$$
[\{\text { status": "OK" }\}]
$$

Fungsi kedua adalah sebagai layer untuk menerima permintaan (request) dari web atau aplikasi mobile, kemudian mengembalikan (response) data yang telah di request dalam format JSON melalui protokol HTTP. Berikut adalah alamat URL untuk request data volume berdasarkan kode pelanggan.

http://inbistro.net/tirton/API/02/

meter_pelanggan.php?a=\{kode pelanggan $\}$

Output data menggunakan format JSON sebagai berikut.

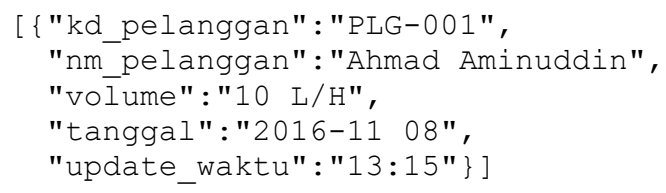

Fungsi ketiga adalah memberikan log data pencatatan meter air yang tersimpan di database. Log data ini memuat informasi pencatatan meter air setiap tanggal yang di filter berdasarkan kode pelanggan, bulan dan tahun. Berikut adalah alamat URL untuk request log data.

http: / / inbistro.net/tirton/API/02/

log_meter_pelanggan.php? $\mathrm{a}=\{\mathrm{kode}$ pelanggan $\} \& \mathrm{~b}=\{$ bulan $\} \& \mathrm{C}=\{$ tahun $\}$ 
Output data menggunakan format JSON sebagai berikut.

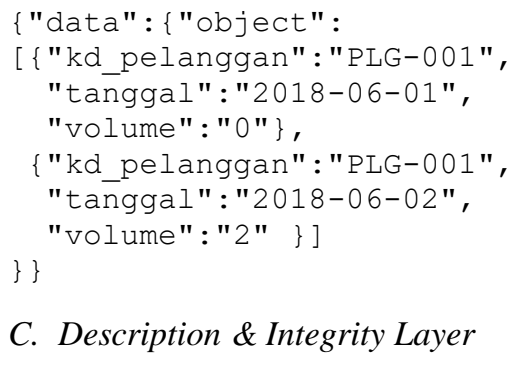

\section{Description \& Integrity Layer}

Description \& integrity layer berfungsi untuk melakukan kontrol terhadap service yang di sediakan. Setiap service yang di sediakan harus di daftarkan terlebih dahulu di Layer ini. Adapun service yang terdaftar antara lain service penyimpanan data node, service data volume dan service data $\log$.

\section{Data Processing Layer}

Data processing layer berfungsi untuk mengolah data berdasarkan request dari pengguna (di terima dari Context Application Layer). Data yang diterima dari service penyimpanan data node dikategorikan berdasarkan kode pelanggan. Data tersebut akan disimpan ke table tb_meter_air_pelanggan. Data request yang diterima dari service data volume di lakukan query ke table tb_meter_air_pelanggan berdasarkan kode pelanggan dengan mengambil data terakhir untuk mendapatkan volume. Data yang dihasilkan dari service data log didapatkan dari query ke tb_meter_air_pelanggan berdasarkan bulan, tahun dank ode pelanggan.

\section{E. Context Database}

Context Database terdiri dari Database Sistem yang berfungsi mengolah data penggunaan air pelanggan dan yang kedua adalah Database Log yang berfungsi untuk menyimpan $\log$ atau catatan mengenai operasi dari tiap node.

\section{F. Host}

Host adalah platform yang di gunakan oleh user agar dapat berinteraksi ke sistem. Dengan menggunakan model Service Oriented Architecture, maka platform yang di dukung sangat fleksibel dan dapat di akses melalui media Smartphone, Web atau Desktop. User yang dapat diakses oleh petugas, operator dan pelanggan.

\section{HASIL DAN PEMBAHASAN}

Pada penelitian ini dikembangkan dua aplikasi. Pertama aplikasi berbasis web digunakan oleh operator. Dalam aplikasi ini operator dapat memantau meter air pelanggan dan volume air yang telah digunakan secara periodik yaitu perbulan dan pertahun. Selain itu operator juga dapat mengetahui lokasi pelanggan yang terpasang meter air digital. Kedua aplikasi berbasis mobile yang digunakan oleh pengguna. Dalam aplikasi ini pengguna dapat mengetahui volume air yang telah digunakan dan log data yang dipilih berdasarkan bulan.
Aplikasi web dikembangkan dengan menggunakan pemrograman PHP, HTML dan Javascript. Berikut adalah tampilan dashboard aplikasi web yang ditunjukan pada gambar 6.

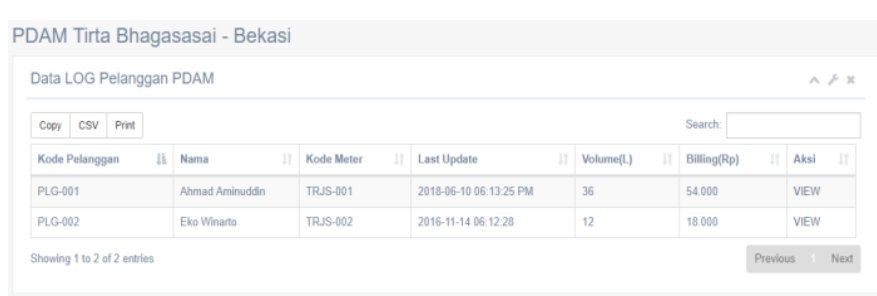

Gbr. 6 Tampilan Dashboard Aplikasi Web

Dashboard aplikasi web menampilkan daftar pelanggan yang telah terpasang meter air digital. Untuk melihat detail informasi setiap pelanggan dapat dilihat dengan klik tombol view. Informasi yang disajikan ada dua yaitu pertama dalam bentuk infografis volume air yang digunakan berdasarkan tahun dan bulan. Pada saat dipilih berdasarkan bulan maka akan menampilkan grafik penggunaan volume air dari tanggal awal sampai akhir bulan. Berikut tampilan detail informasi pelanggan dalam bentuk infografis yang ditunjukan pada gambar 7 .

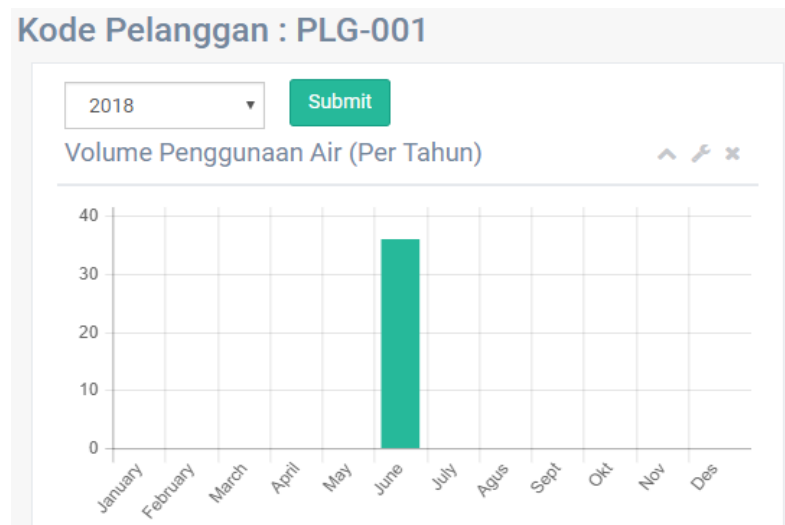

Gbr. 7 Tampilan Infografis Pertahun Pelanggan Melalui Aplikasi Web

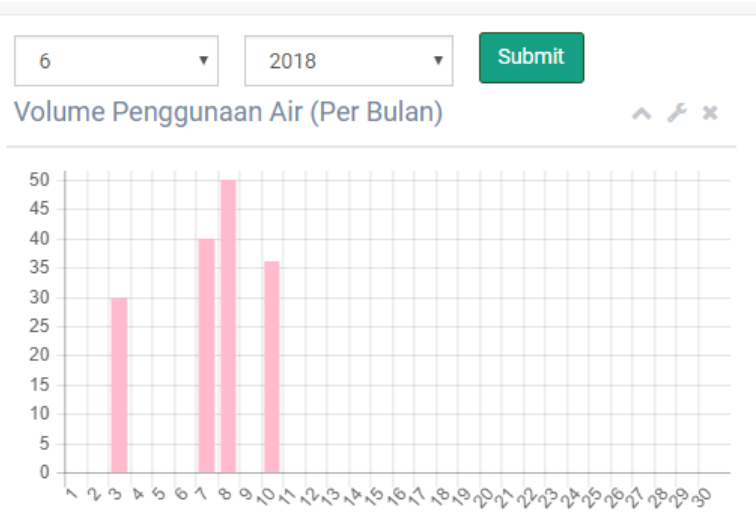

Gbr. 8 Tampilan Infografis Perbulan Pelanggan Melalui Aplikasi Web

Berikut adalah tampilan informasi lokasi pelanggan yang telah terpasang alat pencatatan meter air digital. 


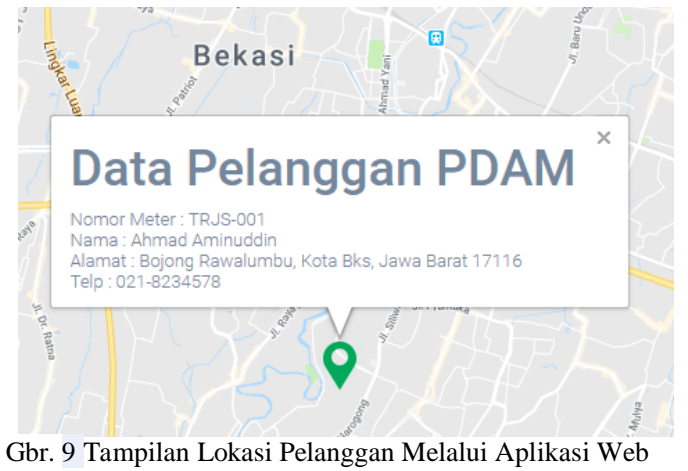

Aplikasi mobile dikembangkan menggunakan framework phonegap, desain boostrap, html, css dan javascript. Berikut tampilan aplikasi mobile.

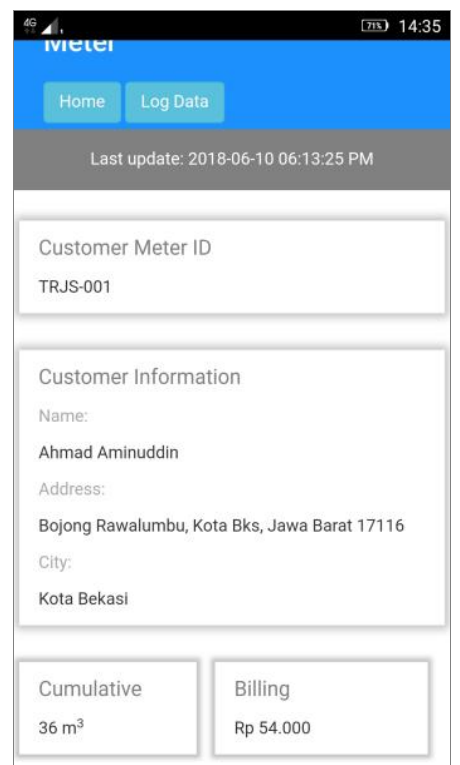

Gbr. 10 Tampilan Dashboard Aplikasi Mobile

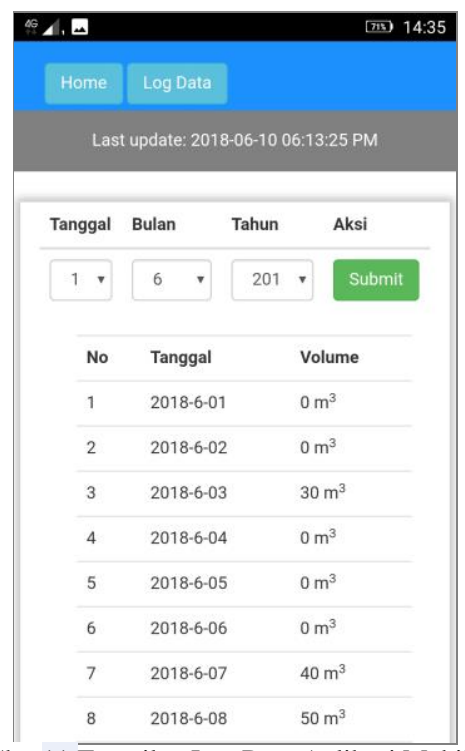

Gbr. 11 Tampilan Log Data Aplikasi Mobile
Pada gambar 9, aplikasi mobile menampilkan informasi kode meter pelanggan, nama, alamat, kota, jumlah volume air yang telah digunakan dan total tagihan. Untuk melihat detail log data dengan cara klik menu Log Data. Pada gambar 10, aplikasi mobile menampilkan log data penggunaan air. Log data penggunaan air tampil setelah dipilih bulan dan tahun terlebih dahulu.

Pengujian dilakukan setelah alat pencatatan meter air telah terhubung ke server. Ada dua jenis pengujian yang dilakukan yaitu pengujian transmisi data dari alat pencatatan meter air ke server, pengujian akses data dari aplikasi web dan mobile, pengujian penggunaan platform yang berbeda pada node dan pada sistem operasi smartphone.

TABEL IV.

PENGUJiAn TRANSMISI DATA

\begin{tabular}{|c|c|c|c|c|}
\hline No & $\begin{array}{c}\text { Waktu } \\
\text { Kirim }\end{array}$ & $\begin{array}{c}\text { Waktu } \\
\text { Terima }\end{array}$ & $\begin{array}{c}\text { Selisih } \\
\text { Detik }\end{array}$ & Keterangan \\
\hline 1 & 14.15 .15 & 14.15 .21 & 6 & Diterima \\
\hline 2 & 14.15 .45 & 14.16 .01 & 16 & Diterima \\
\hline 3 & 14.16 .15 & 14.16 .41 & 26 & Diterima \\
\hline 4 & 14.16 .45 & 14.17 .21 & 36 & Diterima \\
\hline 5 & 14.17 .15 & 14.18 .00 & 45 & Diterima \\
\hline 6 & 14.17 .45 & 14.18 .40 & 55 & Diterima \\
\hline 7 & 14.18 .15 & 14.19 .20 & 66 & Diterima \\
\hline 8 & 14.18 .45 & 14.20 .01 & 77 & Diterima \\
\hline 9 & 14.19 .15 & 14.20 .40 & 86 & Diterima \\
\hline 10 & 14.19 .45 & 14.21 .19 & 95 & Diterima \\
\hline 11 & 14.20 .15 & 14.21 .59 & 105 & Diterima \\
\hline 12 & 14.20 .45 & 14.22 .39 & 115 & Diterima \\
\hline 13 & 14.21 .15 & 14.23 .19 & 126 & Diterima \\
\hline 14 & 14.21 .45 & 12.23 .58 & 135 & Diterima \\
\hline 15 & 14.22 .15 & 14.24 .38 & 145 & Diterima \\
\hline 16 & 14.22 .45 & 14.25 .18 & 155 & Diterima \\
\hline 17 & 14.23 .15 & 14.25 .57 & 164 & Diterima \\
\hline 18 & 14.23 .45 & 14.26 .37 & 174 & Diterima \\
\hline 19 & 14.24 .15 & 14.27 .17 & 185 & Diterima \\
\hline 20 & 14.24 .45 & 14.27 .57 & 195 & Diterima \\
\hline 21 & 14.25 .15 & 14.28 .36 & 204 & Diterima \\
\hline 22 & 14.25 .45 & 14.29 .16 & 214 & Diterima \\
\hline 23 & 14.26 .15 & 14.29 .56 & 224 & Diterima \\
\hline 24 & 14.26 .45 & 14.30 .36 & 234 & Diterima \\
\hline 25 & 14.27 .15 & 14.31 .17 & 246 & Diterima \\
\hline 26 & 14.27 .45 & 14.31 .55 & 254 & Diterima \\
\hline 27 & 14.28 .15 & 14.32 .36 & 265 & Diterima \\
\hline 28 & 14.28 .45 & 14.33 .15 & 274 & Diterima \\
\hline 29 & 14.29 .15 & 14.33 .55 & 284 & Diterima \\
\hline 30 & 14.29 .45 & 14.34 .35 & 294 & Diterima \\
\hline & & & & \\
\hline
\end{tabular}

Waktu pengiriman data dicatat pada saat Arduino mengirim data ke server. Interval waktu yang digunakan adalah setiap 30 detik data akan dikirim ke server. Pengiriman data dari Arduino ke Server melalui service Context Application Layer dengan alamat 
http://inbistro.net/tirton/API/01/send.php?a=\{ meter pelanggan\}

Waktu terima data dicatat pada server ketika mendapatkan data dari Arduino, kemudian di simpan kedalam database pada server. Pengujian transmisi dilakukan sebanyak 30 kali dengan metode pengamatan dan kemudian dianalisis menggunakan grafik berikut.

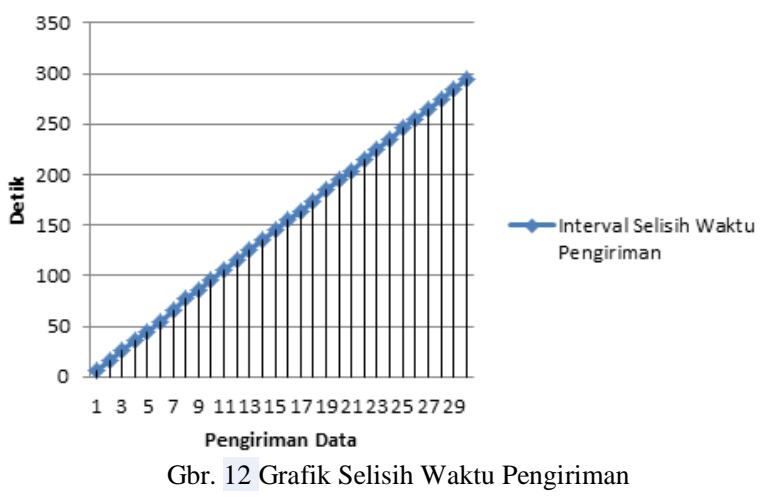

Berdasarkan grafik selisih waktu pengiriman diatas, dapat diimpretasikan bahwa selisih waktu penerimaan data semakin bertambah dan bergerak secara linier. Berikut adalah persamaan linier dari hasil grafik di atas.

Keterangan:

$$
\mathrm{Y}=-0.193+1.324 \mathrm{X}
$$

$\mathrm{Y}=$ Selisih waktu pengiriman data.

$\mathrm{X}=$ Waktu pengiriman data

TABEL V

PENGUJiAn MUlTiPlatForm APLiKASI MobiLe

\begin{tabular}{|c|l|l|c|}
\hline No & \multicolumn{1}{|c|}{ Platform } & Akses Data & Keterangan \\
\hline 1 & $\begin{array}{l}\text { Sistem operasi } \\
\text { Android }\end{array}$ & $\begin{array}{l}\text { Request } \\
\text { data volume }\end{array}$ & OK \\
\hline 2 & $\begin{array}{l}\text { Sistem operasi } \\
\text { Android }\end{array}$ & $\begin{array}{l}\text { Request } \\
\text { data log }\end{array}$ & OK \\
\hline 3 & $\begin{array}{l}\text { Sistem operasi } \\
\text { Microsoft }\end{array}$ & $\begin{array}{l}\text { Request } \\
\text { data volume }\end{array}$ & OK \\
\hline 4 & $\begin{array}{l}\text { Sistem operasi } \\
\text { Microsoft }\end{array}$ & $\begin{array}{l}\text { Request } \\
\text { data log }\end{array}$ & OK \\
\hline 5 & $\begin{array}{l}\text { Mikrokontroller } \\
\text { Arduino }\end{array}$ & $\begin{array}{l}\text { Pengiriman } \\
\text { data volume }\end{array}$ & OK \\
\hline 6 & $\begin{array}{l}\text { Mikrokontroller } \\
\text { Raspberry Pi }\end{array}$ & $\begin{array}{l}\text { Pengiriman } \\
\text { data volume }\end{array}$ & OK \\
\hline
\end{tabular}

\section{IV.PENUTUP}

Berdasarkan hasil pengembangan dengan menggunakan Service Oriented Architecture dapat dijadikan solusi untuk sistem komunikasi data pada perangkat internet of things dalam hal ini alat pencatatan meter air. Service Oriented Architecture dapat digunakan pada perangkat internet of things yang menggunakan Arduino UNO dan Raspberry Pi.
Pada saat pengujian transmisi data, rentang waktu pengiriman data dari perangkat ke server telah diatur yaitu setiap tiga puluh detik. Hasil pengujian transmisi data menunjukkan memiliki selisih pengiriman dan penerimaan data yang cukup besar. Hal ini menyebabkan penerimaan data pada server menjadi lebih lama. Diperlukan penelitian lanjutan untuk mencari solusi agar selisih antara waktu pengiriman dan penerimaan tidak besar.

\section{UCAPAN TERIMA KASIH}

Ucapan terima kasih disampaikan kepada para pihak yang telah membantu dalam menyelesaikan penelitian ini antara lain pihak Direktorat Riset dan Pengabdian Masyarakat (DRPM) Kemenristekdikti yang telah memberikan dana hibah melalui skema Penelitian Dosen Pemula (PDP) dan pihak Universitas Trilogi yang telah mendukung fasilitas penunjang dalam pelaksanaan penelitian.

\section{REFERENSI}

[1] MacGillivray Carrie, Morales Mario. Worldwide and Regional Internet of Things (IoT) 2014-2020 Forecast: A Virtuous Circle of Proven Value and Demand. 2014. International Data Corperation.

[2] Nugroho Budi Raharjo, Thomas Sri Widodo, Adhi Susanto, "Sistem Monitoring Volume Air Pada Meteran Air PDAM Menggunakan Media Komunikasi SMS". Jurnal Penelitian Teknik Elektro, Vol.3, No.3, pp.294-298, September 2010. [Online]. Avaliable: http://ilib.ugm.ac.id/jurnal/detail.php?dataId=12582. [Accessed Jun, 21 2018]

[3] Syahrul, Pamuji Raharjo, "Aplikasi Pencatatan Meter Air Berbasis Smartphone Android", 7 November 2016. [Online]. Avaliable: http://elib.unikom.ac.id/download.php?id=213844. [Accessed Jun, 21, 2018]

[4] Fábio Victor Schreiber, Roberto Alexandre Dias, Victoria Zanetti Marçal Gallo, "Remote Water Consumption Metering using MQTT over Sub-gigahertz RF Environment". International Journal of Computer Applications, Vol.180, No.51, pp.10-17, June 2018.

[5] Amin Suharjono, Listya Nurina Rahayu, Roudlotul Afwah, "Aplikas Sensor Flow Water Untuk Mengukur Penggunaan Air Pelanggan Secara Digital Serta Pengiriman Data Secara Otomatis Pada PDAM Kota Semarang". Jurnal TELE, Vol.13, N0.1, pp.7-11, Maret 2015

[6] BC-Robotics, "Using A Flow Sensor With Arduino", BC-Robotics, 2018. [Online]. Available: https://www.bcrobotics.com/tutorials/using-a-flow-sensor-with-arduino/. [Accessed: Sept. 03, 2018].

[7] Endaryono, Harianto, Wibowo, "RANCANG BANGUN SISTEM PEMBAYARAN MANDIRI PADA WAHANA PERMAINAN", Journal of Control and Network Systems, Vol. 3, No. 1, pp.70-77, 2014

[8] Mardani, Yohandri, Kamus, "PEMBUATAN ALAT UKUR DEBIT AIR MENGGUNAKAN SENSOR ALIRAN BERBASIS MIKROKONTROLER ATMEGA328P", PILLAR OF PHYSICS, Vol 8, pp.105-112, Oktober 2016

[9] Suharjono Amin, Rahayu Listya Nurina, Afwah Roudlotul, "Aplikasi Sensor Flow Water Untuk Mengukur Penggunaan Air Pelanggan Secara Digital Serta Pengiriman Data Secara Otomatis Pada PDAM Kota Semarang". Jurnal Tele. Vol. 13.No.1. pp.7-12, 2015

[10] Vanani Kirit, Patoliya Jignesh, Patel Hardik. "A Survey: Embedded World Around MQTT Protocol for IoT Application", International Journal for Scientific Research \& Development. Vol. 4, Issue 02. pp. 26-29, 2016

[11] Patel K.K, Patoliya J, Patel H, "Low Cost Home Automation with ESP8266 and Lightweight protocol MQTT", Transactions on Engineering and Sciences; 3(6):14-19, 2015

[12] Papazoglou, M.P., and Georgakopoulos, "Service Oriented Computing: Introduction", Communications of the ACM, 46(10), pp. 25-28, 2003 